\title{
Home grown heterosexually acquired HIV infection
}

\author{
Still difficult to predict
}

The public and the health professions might well feel confused about the heterosexual spread of HIV in the United Kingdom. Press headlines swing from dire warnings of a major epidemic to arguments based on the available data that the risks are minuscule, the public education campaigns erroneous, and the policy makers guilty of scare mongering.

Two articles published by the Communicable Disease Surveillance Centre last month help to clarify the situation, if not to resolve the uncertainty about future heterosexual spread. ${ }^{12}$ Evans et al reported that by the end of last year 417 cases of AIDS and 1620 cases of HIV-1 infection probably acquired through heterosexual intercourse had been reported in people in England, Wales, and Northern Ireland. Between 1986 and 1991 the proportion of cases of AIDS attributable to heterosexual transmission increased from $2 \%$ to $14 \%$ and diagnosed HIV infections from $4 \%$ to $23 \%$. ${ }^{3}$ Similar increases have been reported from Edinburgh, southern Europe, and the United States, particularly in association with concurrent epidemics among injecting drug misusers..$^{3-6}$

Most of the heterosexually acquired cases of HIV infection and AIDS in England, Wales, and Northern Ireland, however, are attributable to sexual contact in parts of the world where heterosexual transmission predominates (largely sub-Saharan Africa). ${ }^{1}$ The recent public debate has focused on the lack of prominence given to this epidemiological fact in public health campaigns and an ill defined feeling that infection acquired abroad can be discounted because it does not involve heterosexual transmission within the United Kingdom.

Evans et al defined three categories of heterosexual transmission. "First generation transmission" describes heterosexual transmission of HIV infection from a partner infected by other means - for example, injecting drug misuse, blood products, or sex between men. "Second generation transmission" describes heterosexual infection by partners who were themselves infected through heterosexual intercourse. Cases of second generation transmission are subdivided according to where infection is presumed to have occurredeither abroad or in the United Kingdom.

Ten per cent of cases of AIDS acquired heterosexually ( $17 \%$ of HIV infections) were due to first generation transmission, with injecting drug misuse the commonest route of infection in the source partners. Four out of five cases of heterosexually acquired AIDS (74\% of HIV infections) were categorised as due to second generation transmission abroad. Second generation transmission in England, Wales, and Northern Ireland accounted for $11 \%(n=47)$ of cases of heterosexually acquired AIDS and 9\% $(n=131)$ of cases of heterosexually acquired HIV infection, showing a consistent annual increase. ${ }^{+}$

From detailed interviews Gilbart et al have provided 15 case histories of people infected by heterosexual intercourse whose partners had no history of major risk factors or of sexual contact abroad. ${ }^{2}$ Although in some cases the chain of transmission is not entirely clear, the authors argue that the weight of evidence points to second generation transmission in the United Kingdom. As these and other observers emphasise available reports considerably underestimate heterosexually acquired HIV infection because only people coming forward for testing are included, and many cases are disclosed only when symptoms occur. ${ }^{127}$

These papers and a recent report from Edinburgh provide the first systematic evidence of second generation transmission in the United Kingdom. ${ }^{125}$ But even given the caveats of underestimation, the problem currently remains small. Preoccupation with second generation transmission reflects concern about the possible size of a purely heterosexual epidemic in the British population who do not inject drugs. But getting caught up with this issue gets us nowhere. We cannot regard the heterosexual British population as isolated from the drug injecting population or people from other countries. Many sexually transmitted diseases have been introduced from elsewhere (syphilis from continental Europe in the fifteenth century, penicillinase producing gonococci from parts of Asia in the 1970s, HIV from the United States in the 1980s) and have subsequently thrived locally. As HIV spreads in parts of the world where we have close sexual and other contact there is no reason why the United Kingdom should be spared further second generation transmission. We are observing a series of interacting epidemics and after only 10 years it is not surprising that we can still trace chains of transmission to the early epicentres.

The suggestion that previous forecasts have foretold indiscriminate spread in the heterosexual population is at odds with the conclusions of two national working parties on predicting the course of the epidemic. ${ }^{89}$ These emphasised the great uncertainty concerning future heterosexual spread, which may develop over a much longer time course than the epidemics seen in gay men and drug misusers. Herein lies the key to our difficulties. It is as erroneous to arrive at conclusions in the early 1990s about the eventual prevalence of HIV as it would have been to expect fifteenth century epidemiologists in the decade after the introduction of 
syphilis to predict its devastating effect throughout Europe in subsequent centuries. We must look to continuing surveillance to help resolve the unanswered questions.

Evidence of only limited second generation transmission in the United Kingdom has led some to criticise public education campaigns. ${ }^{10}$ They have argued that too little attention has been paid to the considerable geographical variation in the prevalence of HIV infection and the importance of other major risk behaviours of sexual partners. Should prevention campaigns be directed solely at those at highest risk or is an approach also aimed at the general population the right one? Limiting our efforts to those at highest risk may be shortsighted. Our concept of high risk has evolved as the epidemic has spread - for example, in the early 1980s risk was restricted to gay men who reported sexual intercourse with partners in the United States.

The world does not divide neatly into those at high risk and those at low risk. Epidemics of sexually transmitted diseases are determined by rates of change of sexual partners and patterns of sexual mixing as well as by the transmission efficiencies of organisms. "British data suggest considerable heterogeneity in the number of sexual partners people have in a lifetime, and people may change their risk category as they move from periods when they change partners rapidly to periods when they have a more settled sexual lifestyle. ${ }^{12}$ As those with high risk lifestyles may mix with those with low risk lifestyles both parties need to be informed of the risks of sexually transmitted infection. Prospective sexual partners do not come with a log book of their past partners and experiences, and many heterosexual people will not be aware of their partners' risks. ${ }^{2}$ Perhaps the most important lesson to be learnt from the accounts of second generation heterosexual transmission in the United Kingdom is that many of those infected did not perceive themselves as at risk. ${ }^{12}$

Uncertainty is a difficult message to put across. It neither sells newspapers nor makes good television. Scientists must be honest about where uncertainty lies. But the public should accept that scientists have a duty to warn. We should be prepared to act on this potential threat and invest in self protection in the face of it. Only then will the historians of the next millenium be able to congratulate us on "preventing the epidemic that never happened."

ANNE M JOHNSON

Senior Lecturer in Epidemiology,

Academic Department of Genitourinary Medicine,

University College and Middlesex School of Medicine,

London WIN 8AA

1 Evans BG, Noone A, Mortimer JY, Gilbart VZ, Gill ON, Nicoll A, et al. Heterosexually acquired HIV'-1 infection in. England, Wales and Northern Ireland. Communicable Disease Report 1992;2:R49-55.

2 Gilbart VL, Evans BG, Noone A, Mortimer JY, Gill ON. Second generation heterosexual transmission of HIV-1 infection. Communicable Disease Report 1992;2:R55-59.

3 Centers for Disease Control. HIV/AIDS surveillance US AIDS cases reported through December 1991. Washington, DC: US Department of Health and Human Sciences, 1992.

4 European Centre for Epidemiological Monitoring of AIDS. AIDS surveillance in Europe to $31 \mathrm{st}$ December 1991; quarterly report No 32. Paris: European Centre for Epidemiological Monitoring of AIDS, 1992

5 Willocks L, Hamilton B, Povey S, Brettle R. HIV seroprevalence and antenatal clinics. Lance 1992;339:622.

6 Moss A. AIDS and intravenous drug users: the real heterosexual epidemic. BMF 1987;294:389-90

Ades AE, Parker S, Bury T, Holland SJ, Davison CF, Cubitt D, et al. Prevalence of maternal HIV-1 infection in Thames regions; results from anonymous unlinked neonatal testing. Lancet 1991;337:1562-4.

8 Department of Health and Welsh Office Working Group. Short term prediction of HIV' infection and AIDS in England and Wales. London: HMSO, 1988.

9 Working Group. Acquired immunedeficiency syndrome in England and Wales to end 1993. Projections using data to end September 1989. Communicable Disease Report January 1990:1-12. Projections using data to end September 1989. Communicable Disease Repor
Fernand D, Gerard J. Don't believe the hype. Sunday Times 1992 March $4: 1$.

10 Fernand D, Gerard J. Don't believe the hype. Sunday Times 1992 . March 4:1.
11 May RM, Anderson RM. Transmission dynamics of HIV infection. Nature 1987;326:137-47.

11 May RM, Anderson RM. Transmission dynamics of HIV infection. Nature 1987;326:137-47. Wellings K, Field J, Wadsworth J, Johns
under scrutiny. Nature 1990;348:276-8.

\section{Diagnosing pulmonary embolism}

\section{If the lung scan is non-diagnostic attention should turn to the proximal leg veins}

The importance of establishing the diagnosis in a case of suspected pulmonary embolism is beyond doubt. Clinical trials in the early 1960s established the untreated condition's high mortality (30\%) and the effectiveness of giving anticoagulants.' Continuous intravenous heparin provides immediate and almost complete protection against recurrence of embolism ${ }^{2}$ and should therefore be started as soon as the diagnosis is suspected. On the other hand, anticoagulants are not without risk: heparin given by continuous intravenous infusion for seven days carries a $5 \%$ risk of major haemorrhage; warfarin given for three months an $8 \%$ risk. ${ }^{3} \mathrm{~A}$ vigorous attempt should therefore be made to substantiate the diagnosis before anticoagulants are continued long term.

Although reviews traditionally conclude that pulmonary angiography should be used much more widely to diagnose pulmonary embolism, ${ }^{+}$little evidence exists that this advice is taken. A recent British survey found that only one third of acute hospitals could provide the service, and in these pulmonary angiography was performed on average four times a year for suspected pulmonary embolism. ${ }^{5}$

Since its introduction in the 1960s the radioisotope ventilation-perfusion lung scan has dominated the investigation of this disease: a simple, minimally invasive test that is cheap and quick to perform and has reasonable specificity. A steady flow of retrospective studies in the 1970s comparing this technique with the definitive investigation of pulmonary angiography has recently been refined by two prospective studies. ${ }^{67}$ These have identified two groups in whom a therapeutic decision can be made. The first is patients with a "high probability" scan result (10-20\% of patients), which means the presence of multiple segmental or lobar defects in perfusion that are unmatched by defects in ventilation. Patients with such a scan result have a near $90 \%$ chance of embolism and should be given anticoagulants ${ }^{67}$ unless there is a history of previous embolism - probably the commonest cause of a false positive result - in which case comparison with old scans is desirable.

The second group consists of patients with a normal or near normal scan (15-40\% of patients), in whom the diagnosis can be virtually excluded. In these patients another cause for the symptoms should be sought. In all other cases $(40-70 \%$ of patients) the scan result should be regarded as nondiagnostic. Although scans from such patients may be categorised into various subsets with different probabilities of embolism, this does not solve the clinician's problem because the overall rate of angiographically proved embolism in this group is about $40 \% .{ }^{67}$

These findings have not, apparently, greatly influenced current clinical practice. Doctors are still relying on results of lung scans to decide patients' management without resorting to pulmonary angiography to clarify the diagnosis. ${ }^{8}$ The reasons for this are clear: angiography is relatively expensive, time consuming, and perceived to be risky. The last of these is a misconception. In skilled hands the procedure carries little 